\title{
A habilidade motora de chute: relações entre experiência, sexo e estágio motor La habilidad motora de pateo: relaciones entre experiencia, sexo y etapa motriz The motor skill of kicking: relations between experience, sex and motor stage *Manoella Michel Kucharski, *Ednaldo da Silva Pereira Filho, **Jesús Molina Saorín *Universidade do Vale do Río dos Sinos (Brasil)**Universidad de Murcia (España)
}

\begin{abstract}
Resumo. O presente estudo teve por objetivo analisar e discutir as relações entre experiências motoras, sexo e estágio motor. A pesquisa é um estudo de caráter quanti-qualitativo com amostra probabilística composta por 140 alunos de sete a 10 anos. Nesta pesquisa participaram 72 meninos e 68 meninas com média de idade de 8.57 e um desvio padrão de 1.08. A coleta dos dados motores se deu a partir do teste qualitativo descrito pelos autores Gallahue e Ozmun (2005). O movimento avaliado é a habilidade motora de chute e a sua classificação se realizou de acordo com os estágios motores (inicial, elementar e maduro). Os dados sobre experiência motora foram coletados através de um questionário sobre a rotina diária dos participantes. Ambos instrumentos aplicados neste estudo foram anteriormente validados pelo Método Delphy. Para a análise foi utilizado o teste de qui quadrado (associação de variáveis p <.05) sobre as categorias: experiência motora, sexo e estágios motores. Encontrou-se diferença significativa entre as categorias sexo e estágio motor. O presente estudo revelou uma defasagem motora demonstrada pelos baixos índices de proficiência do movimento. Os dados também apontaram para um desempenho motor mais eficaz do sexo masculino. Sendo assim, é importante repensar de que maneira se está desenvolvendo o estímulo e orientação motora (direcionada ou não) entre ambos os sexos em espaços onde eles vivenciam suas essas experiências.
\end{abstract}

Palavras-chave: Experiência motora, sexo, habilidades fundamentais, crianças; estágio motor.

Resumen. El presente estudio tuvo como objetivo analizar y discutir las relaciones entre las experiencias motoras, el sexo y la etapa motriz. La investigación es un estudio de tipo cuantitativo y cualitativo con una muestra probabilística compuesta por 140 estudiantes entre siete y 10 años. Participaron del estudio 72 niños y 68 niñas, la edad promedio fue 8.57 años con una desviación estándar de 1.08 . La recopilación de datos motores se basó en la prueba cualitativa descrita por los autores Gallahue y Ozmun (2005). El movimiento evaluado es la habilidad motora de pateo y su clasificación se realizó de acuerdo con las etapas motrices (inicial, elemental y madura). Los datos sobre la experiencia motora se obtuvieron mediante un cuestionario sobre la rutina diaria de los participantes. Ambos instrumentos aplicados en este estudio fueron previamente validados por el Método Delphy. La prueba de chi cuadrado (asociación de variables $p<.05$ ) fue utilizada para el análisis de las categorías: experiencia motora, sexo y etapas motrices. Si encontró una diferencia significativa entre las categorías de sexo y etapa motora. El presente estudio reveló un retraso motor demostrado por los bajos niveles de dominio del movimiento. Los datos también apuntan a un rendimiento motor masculino más efectivo. Por lo tanto, es importante replantear cómo se está desarrollando la estimulación y orientación motriz (dirigida o no) entre ambos sexos en los espacios donde experimentan estas experiencias.

Palabras clave: experiencia motora, sexo, habilidades fundamentales, niños; etapa motora.

\begin{abstract}
The present study aimed to analyze and discuss the relationships between motor experiences, sex and motor stage. The research is a quantitative and qualitative study with a probabilistic sample composed of 140 students aged seven to 10 years. The 72 boys and 68 girls have participated in this research with an average age of 8.57 and with a standard deviation of 1.08. The collection of motor data was based on the qualitative test described by the authors Gallahue and Ozmun (2005). The evaluated movement is the kicking motor skill and its classification was made according to the motor stages (initial, elementary and mature). Data on motor experience were collected through a questionnaire about the participants' daily routine. Both instruments applied in this study were previously validated by the Delphy Method. The chi square test (association of variables $p<.05$ ) was used for the analysis of categories: motor experience, sex and motor stages. We found a significant difference between the sex and motor stage categories. The present study revealed a motor lag demonstrated by the low levels of movement proficiency. The data also pointed to a more effective male motor performance. Therefore, it is important to rethink how motor stimulation and orientation (directed or not) is developing between both sexes in spaces where they feel these experiences.
\end{abstract}

Keywords: Motor experience, sex, fundamental skills, children; motor stage.

\section{Introdução}

Segundo Gallahue e Ozmun (2013, p.21), «o desenvolvimento motor é a mudança contínua do comportamento motor ao longo do ciclo da vida, provocada pela interação entre as exigências da tarefa motora, a biologia do indivíduo e as condições do ambiente». Para MéridaSerrano, Olivares-García e González-Alfaya (2018, p.330), «constitui uma conquista natural na qual as crianças vão garantindo mediante seu desejo de interatuar com o seu



próprio corpo e com a realidade que rodeia os outros, os objetos, o espaço e o tempo». De acordo com Haywood e Getchell (2004, p.344), «é um processo sequencial, contínuo e relacionado à idade cronológica», portanto, a mesma foi utilizada como critério de inclusão dos alunos no estudo. Neste trabalho foram analisados dois aspetos: tarefa (experiência motora) e indivíduo (sexo).

Segundo Mérida-Serrano et al. (2018), a faixa etária de 0 aos 6 anos é essencial para o desenvolvimento integral das crianças. De acordo com García-Marín e Fernandez-López (2020), a pré-escola é um ponto crucial no desenvolvimento do indivíduo. De acordo com Gallahue e Ozmun (2013)é, de fato, nessa etapa em que as crianças aprendem as habilidades motoras fundamentais que serão aprimoradas na próxi- 
ma etapa, denomianada estágio de transição da fase de movimento especializado. Essa etapa do desenvolvimento motor compreende a faixa etária de sete a 10 anos na qual as crianças começam a combinar e aplicar as habilidades de movimentos mais complexos e especializados, com a finalidade de desempenhar atividades como lutas, danças e ginástica. Uma vez que o Instituto Brasileiro de Geografia e

Estatística (IBGE, 2017), aponta o futebol como o esporte mais praticado no Brasil, pressupõe-se que os participante apresentariam um estágio avançado na categoria manipulativa da habilidade motora do chute.

É comum pensar no estereótipo da criança ativa dentro da sua rotina diária, entretanto, diversos autores apontam uma transformação social vinculada ao surgimento e acessibilidade dos aparelhos eletrônicos. Segundo Monsalve e Sánchez (2019, p.307), «os estudantes na sua busca por ferramentas TIC em diversas áreas de aprendizagem e incluindo nos momentos de tempo livre investem muitas horas em frente ao computador, o qual impede ou dificulta o desenvolvimento das habilidades físicas». De acordo com os dados disponibilizados pelo Programa das Nações Unidas para o Desenvolvimento no Brasil (PNUD, 2017), no Brasil: aproximadamente $70 \%$ da população é constituída de não praticantes. Assistimos -assim - a uma mudança no modelo de sociedade, sendo cada vez mais frequente ver as crianças com seus equipamentos eletrônicos em mãos, e já não colocando em prática aqueles jogos tradicionais que evolvem criatividade, contato físico direto, coordenação de acordo com Paiva e Costa (2015) e que foram o centro do lazer infantil das gerações anteriores.

Como sabemos, as crianças passam muito tempo vinculadas à inúmeros objetos eletrônicos, perdendo -entãopossibilidades de estimulação procedentes de outras fontes (clássicas) promotoras do exercício físico, o que MartínezGonzález, Varo, Santos , Irala, Gibney, Keamey e Martínez (2001) apud Heredia, Sanchez, Gallego, Zagalaz e Moral (2019), chamou de uma evolução negativa que afeta diretamente os hábitos relacionados com a atividade física causando um prejuízo no desenvolvimento motor. Atualmente, os dados assustam ao demonstrar o nível de sedentarismo no mundo (estilo de vida que consequentemente reflete no âmbito motor), segundo a Organização Pan-Americana de Saúde (2020), o número de crianças e adolescente obesos aumentou para 124 milhões no ano de 2016. De acordo com Heredia et al. (2019, p.126), «hoje em dia a sociedade mudou completamente, em quase todos os âmbitos, entre eles os hábitos alimentares e as formas de jogar». Além da obesidade infantil e outras doenças relacionadas ao sedentarismo de acordo com a Organização Mundial da Saúde (2019), o mesmo está vinculado com a ausência ou carência de movimento, ou seja, carência de experiência motora que por si é um fator de extrema importância para a aprendizagem motora. De acordo com Schmidt e Wrisberg (2010, p.33), a aprendizagem motora constitui-se como «as mudanças associadas à prática ou experiência em processos internos que determinam a capacidade de um indivíduo para executar uma habilidade motora», tendo como resultado uma melhoria relativamente permanente no desempenho motor, devido à prática ou à experiência de acordo com Magill (1987). A falta de movimento é um dos fatores contribuintes para o atraso motor das crianças. Segundo García-Marín e Fernández- López (2020), dois fatores são de extrema importância para o desenvolvimento do indivíduo, são eles: o estímulo e o ambiente, que devem trabalhar em conjunto exigindo uma constante adaptação do ser humano. Eles também ressaltam a importância das avaliações motoras e cognitivas desde cedo para averiguar as necessidades de cada aluno, esta orientação tem por objetivo a construção de um plano de intervenção para potencializar as habilidades individuais. As mudanças internas necessárias para a aprendizagem motora, portanto, dependem de outros fatores, tais como as experiências vividas, o próprio repertório motor e suas relações com o ambiente, sendo essa relação objeto de análise desta pesquisa.

O estudo de Palma, Guaríglia e Marques-2016-(intitulado «Análise do desenvolvimento motor de crianças em diferentes classes sociais»), apontou uma alta porcentagem de crianças em estágio avançado na habilidade motora de chute, resultado esse que vai de encontro aos dados avaliados nessa pesquisa. O estudo também assinalou um desenvolvimento motor atípico com relação às fases de movimento dos autores Gallahue e Ozmun (2013), ou seja, uma defasagem motora de modo geral. Esse atraso no desenvolvimento pode estar relacionado ao estilo de vida, à baixa carga horária da Educação Física escolar, entre outros fatores que restringem o repertório motor do aluno. Nesse sentido, o presente artigo tem -então-como principal objetivo analisar e discutir as relações entre experiências motoras, sexo e habilidades motoras fundamentais das crianças na faixa etária de sete a 10 anos. Desde essa ótica, foi avaliado o desempenho motor da habilidade de chute e relacionado com as demais variáveis para verificar a possível existência de relações diretas, contribuindo para mais dados na área do desenvolvimento motor, tendo em vista a inexistência de um órgão (público ou privado) avaliador da qualidade motora.

\section{Metodologia}

\section{Desenho do estudo}

A presente pesquisa se caracteriza como um estudo quanti-qualitativo de acordo Thomas, Nelson e Silverman (2012), sendo do tipo ex post fato, segundo Gaya (2008). A coleta de dados foi distribuída em diferentes dias, de acordo com a disponibilidade das turmas selecionadas. $\mathrm{O}$ objetivo consistiu em analisar e discutir os valores obtidos através do questionário e dos testes motores aplicados, assim como suas possíveis relações.

\section{Amostra}

Participaram deste estudo um total de 140 alunos do segundo até o quinto ano do ensino fundamental com idade entre sete e 10 anos. A idade média dos estudantes avaliados é de 8.57 com desvio padrão de 1,08. Os participantes foram divididos pela categoria de sexo, sendo agrupados em 72 meninos ( 8.6 anos de média) e 68 meninas ( 8.5 de média), dispostos em oito turmas em ambos turnos (manhã e tarde). A amostra foi selecionada em conjunto com o responsável pela supervisão escolar, seguindo critérios de disponibilidade horária das turmas. A escola participante é componente da rede municipal da cidade de Gravataí/RS (Brasil). Segundo 
Gaya (2008), a amostra foi probabilística proporcional ao número de turmas e número de alunos. Com um universo de 640 alunos, a amostra foi calculada a partir da referência de uma população finita de acordo com a equação sugerida por Arnal, Rincón e Latorre (1994) apud Gaya (2008, p.91): « $\mathrm{Za}^{2}$.p.q. N/e ${ }^{2}(\mathrm{~N}-1)+\mathrm{Za}^{2}$.p. q». O cálculo feito foi $1^{2} .50 .50$. $\left(640 / 4^{2}\right)(639)+1^{2} .50 .50$ totalizando 125 alunos.

Sabendo-se que inexiste no Brasil indicadores oficiais de qualidade motora, foi adotado - então- como parâmetro na escolha do local da pesquisa a nota obtida pela escola no IDEB. De acordo com o Instituto de Estudos e Pesquisas Educacionais Anísio Teixeira-INEP (2013), o Índice de Desenvolvimento da Educação Básica (IDEB) supõe uma avaliação do sistema educativo (em geral), o que inclui uma série de indicadores que servem de parâmetros para avaliar a qualidade do ensino nas escolas. A escola finalmente selecionada para desenvolver a presente pesquisa pertence a rede Municipal da cidade de Gravataí/RS, e obteve uma classificação no IDEB superior a do Município.

Como critérios de inclusão adotaram-se os seguintes: 1) Estar entre o segundo e o quinto ano do ensino fundamental; 2) Não possuir nenhuma necessidade educacional especial; 3) Ter entre sete e 10 anos. Após a devida autorização da escola, seguiram-se os procedimentos éticos de pesquisa. $\mathrm{O}$ termo de livre consentimento foi enviado a todas as crianças selecionadas.

\section{Instrumentos e tarefa}

Foram utilizados um tripé para apoio da câmera, uma câmera filmadora digital e duas bolas de futebol, de tamanho 3 e 4 . Todos os participantes executaram três vezes o movimento de chute sendo de decisão própria a escolha do membro inferior (esquerdo ou direito) executor da ação. Descrição do movimento: A bola foi posicionada na linha central da quadra poliesportiva. As medidas da quadra e da goleira estão devidamente regulamentadas de acordo com as medidas oficiais brasileiras. Utilizou-se como ponto de partida uma linha desenhada no solo com $5 \mathrm{~m}$ de distância do ponto de execução do movimento. O proposito foi chutar a bola com o objetivo de realizar um gol.

\section{Procedimentos}

O movimento avaliado foi a habilidade motora fundamental de chute da categoria manipulativa. O posicionamento da câmera foi de $45^{\circ}$ com relação ao ponto de aplicação da tarefa. Os participantes foram instruídos sobre a execução e objetivo da atividade proposta antes de serem individualmente

\section{filmados.}

Os vídeos coletados foram dispostos no programa Movavi para análise qualitativa realizada com base nos componentes dos movimentos descritos no modelo de Gallahue e Ozmun (2005), sendo a classificação dividida em estágio inicial, elementar e maduro. Por outra parte, salientamos que no teste motor utilizado os autores descrevem uma série de elementos que assinalam a classificação do movimento de acordo com os estágios citados acima, tendo em vista a necessidade de uma avaliação mais precisa do movimento. Nas fases previas da nossa pesquisa, e tomando em consideração o método científico, discutiu-se e determinou- se o padrão de movimento básico necessário para cada estágio (com base na literatura especializada), ou seja, o movimento -de maneira geral- deveria apresentar tanto uma harmonia visual quanto os principais elementos do movimento estudado. Após a primeira coleta, foi aplicado um questionário aos alunos. Ambos os instrumentos foram validados

anteriormente pelo método Delphy, autorizado por dois professores de Educação Física da Universidade do Vale do Rio dos Sinos (UNISINOS). No mesmo, as crianças responderam sobre suas experiências motoras (se praticam ou não futebol durante a semana), sexo, brincadeiras e locais de prática. Sendo coletados dados além dos analisados nesta pesquisa, que seguem para trabalhos posteriores.

\section{Tratamento dos dados}

Com todos os dados necessários e dispostos em uma planilha no Excel, iniciou-se a análise com o auxílio do software SPSS Statistics (versão 22). Para identificar a natureza estatística dos dados coletados foi realizado o teste de normalidade Shapiro Wilk que apresentou como resultado $\mathrm{p}=.000$ ou seja, os valores não apresentaram distribuição normal, pois foi inferior a .05, e desta forma, são dados não paramétricos. Com esta constatação da natureza de dados foi adotado o teste de qui quadrado (o nível de significância utilizado foi $\mathrm{p}<.05)$.

\section{Resultados}

Nesta seção do trabalho serão feitas as discussões através dos resultados obtidos pelo SPSS e teste de qui quadrado.

Antes de apresentar os dados é importante destacar o perfil identificado desta população como sendo de alunos que estão todos em uma escola básica da rede municipal com idades de sete a 10 anos. Com base nos questionários, esses alunos visualizam como local de prática de atividade física sua casa e a rua e num terceiro âmbito a escola que, de maneira geral, supõe-se que é um ambiente de possibilidades para experiências motoras. Das brincadeiras, as mais citadas foram pega-pega, esconde-esconde e futebol (a última delas envolvendo a habilidade motora analisada neste estudo). Essa informação (coletada através dos questionários), será

apresentada em outros estudos posteriores. $\mathrm{Na}$ continuação, seguem as relações obtidas com esse estudo.

\section{Experiências, sexo e estágios motores}

A amostra total desse estudo foi composta por $48.6 \%$ de meninas $(\mathrm{N}=68)$, e $51.4 \%$ de meninos $(\mathrm{N}=72)$. Os valores representados por idades da amostra geral são os seguintes: $21.42 \%(\mathrm{~N}=30)$ para crianças com sete anos com uma proporção de $50 \%$ de acordo com o sexo, para crianças com oito anos o valor é de $24.28 \%(\mathrm{~N}=34)$ com $47.05 \%$ de meninas e $52.94 \%$ de meninos, para crianças com nove anos o valor da amostra geral foi de $30 \%(\mathrm{~N}=42)$ com proporção de $50 \%$ de acordo com o sexo e por último de acordo com os alunos na faixa etária de 10 anos a porcentagem correspondente foi de $24.28 \%$ na amostra total $(\mathrm{N}=34)$ com $47.05 \%$ de meninas e $52.94 \%$ de meninos. No questionário os alunos responderam se praticavam ou não o futebol durante a se- 
mana, sendo considerados os dados que confirmam prática ao menos duas vezes por semana. Um alto percentual em ambos sexos confirmou a prática semanal do futebol, atingindo o valor de $76.5 \%$ de meninas praticantes $(84.7 \%$ para meninos), e o valor de $23.5 \%$ para meninas não praticantes ( $15.3 \%$ em meninos para não praticantes).

Na Tabela 1 estão dispostos os fatores experiência motora (adquirida por meio da prática) e sexo, ambos associados com as habilidades motoras. De acordo com a análise do grupo de meninas praticantes de futebol, $51.9 \%$ se encontra no estágio inicial, seguido por $32.7 \%$ em estágio elementar e apenas um $15.4 \%$ em estágio maduro. Os dados com relação as alunas não praticantes apresentaram valores de $31.3 \%$ para estágio inicial, $62.5 \%$ para estágio elementar e $6.3 \%$ para estágio maduro. Houve uma predominância entre os estágios inicial e elementar de ambos os grupos com baixa incidência de movimentos proficiente. Os dados do grupo de meninos demonstraram que entre os praticantes $18.0 \%$ obtiveram resultados no estágio inicial, $45.9 \%$ em estágio elementar e $36.1 \%$ em maduro. Entre os meninos não praticantes esses valores foram de $36.4 \%$ para estágio inicial, $54.5 \%$ para estágio elementar e $9.1 \%$ para estágio maduro. Portanto se assinalam menores valores de estágios iniciais em praticantes e maiores valores em elementar e maduro com uma grande diferença no último. O teste de qui quadrado resultou um valor de $\mathrm{p}=.68$ para as variáveis experiência motora e estágios motores, não indicando uma diferença significativa.

\begin{tabular}{|c|c|c|c|c|c|c|c|}
\hline & & & & Estágio & & & Total \\
\hline & & & & Inicial & Elemental & Madura & \\
\hline \multirow{5}{*}{ Femenino } & Prática & Sim & $\begin{array}{l}\text { Quantide } \\
\text { o Prátic }\end{array}$ & $\begin{array}{c}27 \\
51.9 \%\end{array}$ & $\begin{array}{c}17 \\
327 \%\end{array}$ & $\begin{array}{c}8 \\
154 \%\end{array}$ & $\begin{array}{c}52 \\
100 \%\end{array}$ \\
\hline & & Não & Quantide & 5 & 10 & 1 & 16 \\
\hline & & & $\%$ Prática & $31.3 \%$ & $62.5 \%$ & $6.3 \%$ & $100 \%$ \\
\hline & Total & & Quantide & 32 & 27 & 9 & 68 \\
\hline & & & $\%$ Prática & $47.1 \%$ & $39.7 \%$ & $13.2 \%$ & $100 \%$ \\
\hline \multirow{6}{*}{ Masculino } & Prática & Sim & Quantide & 11 & 28 & 22 & 61 \\
\hline & & & $\%$ Prática & $18.0 \%$ & $45.9 \%$ & $36.1 \%$ & $100 \%$ \\
\hline & & Não & Quantide & 4 & 6 & 1 & 11 \\
\hline & & & $\%$ Prática & $36.4 \%$ & $54.5 \%$ & $9.1 \%$ & $100 \%$ \\
\hline & Total & & Quantide & 15 & 34 & 23 & 72 \\
\hline & & & $\%$ Prática & $20.8 \%$ & $47.2 \%$ & $31.9 \%$ & $100 \%$ \\
\hline
\end{tabular}

O maior número de meninas na habilidade motora de chute se encontra no estágio inicial com $47.1 \%$, seguido pelo elementar $39.7 \%$ e por último o maduro $13.2 \%$. Entre os meninos, os resultados demonstraram melhor desempenho sendo a maioria em estágio elementar com $47.2 \%$, seguido pelo maduro $31.9 \%$ e por último inicial $20.8 \%$. Adiferença de porcentagem entre meninos e meninas que praticam futebol é mínima, porém, os resultados dos testes demonstraram uma distância maior no que diz respeito a eficiência de movimento. Os meninos apresentam um maior número relacionado ao estágio maduro da habilidade e menor de inicial, demonstrando -de modo geral- um melhor desempenho motor da habilidade fundamental com relação as meninas neste teste. Na relação sexo- estágio motor no teste de qui quadrado resultou $\mathrm{p}=.002$ o que indica diferença significativa na relação sexo e resultados do teste motor, ou seja, que o fator sexo influenciou no desempenho dessa habilidade. De maneira geral, os dados apontam que as crianças presentes nesse estudo possuem um desenvolvimento motor inferior à sua idade cronológica, ou seja, a fase de movimento na qual se encontram.

\section{Discussão dos resultados}

A descrição de dados exposta na Tabela 1 (entre experiência e estágios motores), de acordo com os valores obtidos não revela uma associação estatisticamente significativa; portanto, não se pode rejeitar a hipótese nula. $\mathrm{Na}$ atual pesquisa, os participantes relataram que experienciam o futebol durante a semana, confirmando que neste caso unicamente a experiência motora (prática) não foi suficiente para o tornar o movimento proficiente, ou seja, próprio de um estágio maduro. Segundo Tani e Correa (2016, p.141), «a prática é um fator fundamental para o sucesso». De acordo com Gallahue e Ozmun (2013, p.72), o estágio proficiente ou maduro «caracteriza-se por performances mecanicamente eficientes, coordenadas e controladas» sendo «as oportunidades de prática, encorajamento, instruções e ecologia do ambiente trabalhando juntamente com a maturação num processo de desenvolvimento das habilidades motoras». Portanto, ainda que a experiência motora seja necessária para a aprendizagem, existem outros fatores que contribuem mutuamente no processo de desenvolvimento motor.

No estudo dos autores Palma, Guariglia e Marques (2016), os alunos avaliados se encontraram basicamente entre os estágios elementar e maduro na habilidade motora de chute, o que vai de encontro com esse estudo devido aos baixos porcentagens em estágio maduro,

entretanto, o número de alunos avaliados foi inferior ao desta pesquisa. Os autores Castro (2016) e Austun e Fogagnoli (2013), constataram uma inferioridade das meninas com relação aos meninos no desempenho motor da habilidade de chute e, de maneira geral, uma defasagem motora de ambos os sexos, fato que se mantém nos resultados desta investigação. Um alto percentual de alunos apresentou um desempenho motor inferior à idade cronológica correspondente. Quanto a relação sexo e estágios motores, o teste de qui quadrado apontou valores que demonstraram uma

uma rejeição da hipótese nula e, portanto, uma associação estatisticamente significativa entre as variáveis, demonstrando os meninos maior nível de eficiência e uma menor porcentagem de casos no estágio inicial. Segundo Azúa, Lillo e Saavedra (2019, p.51), existe uma «socialização de gênero produzida e reproduzida pela escola» de maneira que internaliza papéis aos estudantes, esses papéis podem contribuir para uma igualdade ou

desigualdade. A transferência de papéis tradicionais pode ser um dos fatores causadores das diferenças entre os sexos já que a menina tende a ser «menos ativa» à nível físico que o menino. De acordo com o seu papel, o modo com que se dá o estímulo pode ser outra possível causa das diferenças apresentadas nesse estudo.

Segundo Patraquim, Ferreira, Martins, Mourão, Gomes e Martins (2018), as crianças dispendem muito tempo assistindo à televisão - ergo - em casa, a casa é o primeiro ambiente de socialização dos alunos, seguido pela instituição escolar. Neste cenário, os alunos gastam -no mínimo-quatro horas diárias e estão grande parte do tempo sentados devido as atividades teóricas, tornando o momento da aula de Educação Física o auge do seu gasto energético. Na descrição dos Parâmetros Nacionais de Qualidade para a Educação Infantil (Brasil, 2006), está salientada a importância tanto de 
um espaço físico adaptado assim como, dos diferentes tipos de materiais e objetos que podem auxiliar o docente na intervenção do desenvolvimento das crianças colaborando efetivamente para o seu processo de aprendizagem. Portanto, é necessário discutir-se a qualidade do espaço e das ferramentas escolares disponíveis para o desenvolvimento das atividades e o papel do professor de Educação Física como mediador do conhecimento no meio desse contexto social, orientando, desenvolvendo e aproveitando-se desses instrumentos dispostos no ambiente. Ainda sobre a perspectiva do ambiente, um bom questionamento é o estímulo advindo da família. Segundo Wagner, Tronco, Gonçalves, Demarchi e Levandowski (2012), é importante entender como a família transmite as normas e valores para entender como ela maneja o processo de socialização de uma criança. É de conhecimento comum que a motivação à iniciação nas áreas -por exemplo- vinculadas ao esporte na primeira infância está diretamente vinculada à família tendo em vista a carga horária disposta no ambiente familiar. Sabendo-se que a escola pública utilizada para a obtenção de dados se situa em uma cidade com uma alta população, e considerando a realidade escolar dos alunos que frequentam a rede pública de ensino, pressupomos que o ambiente «casa» pode não estar adequado para o desenvolvimento das habilidades deduzindo que os espaços físicos dispostos são insuficientes para o número de pessoas que o compartilham.

Mesmo que a Educação Física seja disciplina obrigatória em toda a educação básica de acordo com a Lei de Diretrizes e Bases da Educação - LDB (Brasil, 1996), muitos municípios não a contemplam como disciplina, necessariamente, ministrada pelo profissional responsável da área, e fundamentalmente nos anos iniciais da escola básica. Para o aprimoramento do desenvolvimento motor das crianças é necessário um profissional capacitado para exercer a função com base teórica e prática que proporciona o currículo da Educação Física. Geralmente, o professor de Educação Física é requerido a partir dos nove ou 10 anos de idade (momento final da fase de movimentos especializados no estágio transitório). Partindo desse princípio e tendo em vista a importância de uma orientação adequada, temos mais uma possível justificativa no retardo do processo de desenvolvimento das habilidades motoras fundamentais. Outra possível justificativa para o déficit encontrado nos resultados sobre o desempenho dos alunos em idade escolar seria a inadequada estimulação motora decorrente do contexto social. Segundo os autores Delgado, Michelon, Gerzson Almeida e Alexandre (2020, p.53), houve diferença significativa no aspecto econômico apontando « a baixa renda familiar como fator de risco para o desenvolvimento infantil», assim como citado por outros estudos como sendo aspectos importantes a se considerar em uma avaliação motora.

Para um futuro sugerimos o desenvolvimento de estudos que visem analisar quantas das crianças praticam o futebol em um ambiente especializado, ou seja, um clube ou uma escolinha de futebol. A base desta sugestão se deduz que o estímulo está totalmente vinculado ao movimento objeto de estudo.

Os autores Gallahue e Ozmun (2013), comentam em seu livro que muitas pessoas chegam ao estágio elementar de uma habilidade e nele permanecem. A aprendizagem motora tem papel fundamental no avanço de um estágio para outro, sendo a base dela o estímulo. De acordo com Go Tani e Correa (2016, p.19), a aprendizagem motora são «as mudanças no comportamento motor de um indivíduo como resultado da prática, e dos fatores que os influenciam», portanto, existe a necessidade de entender como se está desenvolvendo a prática pelos alunos. Os alunos estão passando pelas fases de desenvolvimento fundamental sem o devido aprimoramento das habilidades. Com o avanço da tecnologia essas crianças estão sendo menos estimuladas a praticarem atividade física e quando praticam não são orientadas devidamente para uma melhoria. É preocupante esse resultado pois estamos seguindo por um lado que pode levar a uma inabilidade motora. Portanto, é necessário proporcionar estímulos motores às crianças para impulsioná-las a aprendizagem motora e, consequentemente, ao aprimoramento das habilidades motoras fundamentais para que possam escolher com eficiência um esporte mais complexo.

\section{Conclusões}

Os resultados das avaliações descritas nesta pesquisa chamaram à atenção para uma defasagem motora (de modo geral). Este estudo, além de contribuir para mais dados na área, dispôs de um processo de pesquisa simples tendo em vista a sua fácil aplicabilidade e a baixa quantidade de material físico requerido para o seu desenvolvimento. Desde essa ótica, sugerimos a sua utilização para fins pedagógicos como ferramenta auxiliar para os professores de Educação Física

no contexto escolar. Com as considerações deste estudo, os profissionais da Educação Física podem usufruir deste instrumento para uma análise inicial e final dos alunos a cada ano, com o intuito de avaliar a evolução dos estudantes contribuindo -assim- para uma intervenção mais eficaz no processo de aprendizagem para o aprimoramento das habilidades.

Como já foi revelado, na relação experiência motora e estágios não houve valores significativos que relacionem os dados investigados, demonstrando que somente vivenciar (experiência) não é suficiente para o aprimoramento completo do movimento. Já na relação entre sexo e estágio foi constatada essa significância; os autores Gallahue e Ozmun (2013) referem-se à tarefa como um dos três fatores envolvidos no processo de mudança do comportamento motor, juntamente com a biologia e o ambiente. Visualizando os resultados das

duas análises obtidas nesta pesquisa, surge a necessidade de questionar como se dá o estímulo entre os sexos nos ambientes de desempenho das habilidades fundamentais para constatar uma possível relação. Considerando a orientação profissional extremamente importante para a correção na aplicação do movimento, sugerirmos este assunto

para outros estudos posteriores.

Para finalizar, podemos concluir que são necessários mais estudos sobre o desenvolvimento motor em contextos reais das crianças nessa faixa etária, o que iria permitir observar a evolução das habilidades motoras tendo em vista a construção de estratégias no âmbito pedagógico que 
possibilitam a intervenção adequada realizada pelos profissionais. Toda vez que a análise da

qualidade motora das crianças se revela como una variável de suma importância, resulta plenamente recomendável elevar a discussão no plano da intervenção realizada pelos profissionais da Educação Física, para então poder potencializar essas habilidades em prol da melhora da motricidade.

\section{Referências}

Austun, C., \& Fogagnoli, A. (2013). Desenvolvimento motor das crianças de seis a oito anos de idade da Escola Municipal 'Monteiro Lobato' do município de Terra Boa, PR. EFDeportes, 177(17). Recuperado de https://www.efdeportes.com/efd177/ desenvolvimento-motor-das-criancas-de-6-a-8.htm

Azua, X., Lillo, D., \& Saavedra, P. (2019). El desafío de una educación no sexista en la formación inicial: prácticas docentes de educadoras de párvulo en escuelas públicas chilenas. Calidad en la educación, (50), 40-82. Recuperado de https:// scielo.conicyt.cl/scielo.php? script $=$ sci_arttext\&pid= S071845652019000100040\&lng=es\&nrm=iso

Brasil, Ministério da Educação- Secretaria da Educação Básica. (2006). Parâmetros Nacionais de Qualidade para a Educação Infantil - Volume 1. Brasília. Recuperado de http:// portal.mec.gov.br/seb/arquivos/pdf/Educinf/ eduinfparqualvoll.pdf

Brasil, Presidência da República do Brasil. (1996). Lei de Diretrizes e Bases da Educação Nacional. Lei número 9394. Recuperado de: http://www.planalto.gov.br/ccivil_03/Leis/L9394.htm

Castro, K. (2016). Aprendizado e estímulo de habilidades motoras Fundamentais em Crianças. Trabalho de Conclusão de Curso (Licenciatura Plena em Educação Física), Universidade Do Vale do Sinos (UNISINOS), São Leopoldo.

Delgado D. A., Michelon R. C., Gerzson L. R., Almeida C. S., \& Alexandre M. G. (2020). Avaliação do desenvolvimento motor infantil e sua associação com a vulnerabilidade social Fisioterapia e Pesquisa, (1), 48-56. Recuperado de: http:// www.scielo.br/scielo.php? script $=$ sci arttext\&pid $=$ $\mathrm{S} 180929502020000100048 \& \operatorname{lng}=\mathrm{en} \& \mathrm{nrm}=\mathrm{iso}$

Gallahue, D., \& Ozmun, J. (2005). Compreendendo o Desenvolvimento motor. Bebês, crianças, adolescentes e adultos. São Paulo: $3^{\circ}$ Edição. Phorte Editora. Gallahue, D., \& Ozmun, J. (2013). Compreendendo o Desenvolvimento motor. Bebês, crianças, adolescentes e adultos. São Paulo: $7^{\circ}$ Edição. Phorte Editora.

García-Marín P., \& Fernández-López N. (2020). Asociación de la competencia en las habilidades motrices básicas con las actividades físico-deportivas extracurriculares y el índice de masa corporal en preescolares. Retos, (38), 33-39. Recuperado de: https://recyt.fecyt.es/index.php/retos/article/view/71896

Gaya, A. (2008). Ciência do Movimento Humano. Introdução à metodologia de pesquisa. Porto Alegre: 1. ${ }^{a}$ Edição. Artemed Editora.

Haywood, K., \& Getchell, N. (2004). Desenvolvimento Motor ao Longo da Vida. $3^{\circ}$ ed. Porto Alegre: Artmed, 344.

Heredia C. M. R., Sánchez A. J. L., Gallego F. J. L., Zagalaz J. C., \& Moral P. V. (2019). Análisis del tiempo de clase en EF y propuestas para su optimización. Retos, (35), 126-129. Recuperado de https://recyt.fecyt.es/index.php/retos/article/view/ 61880

Instituto Brasileiro de Geografia e Estatística (IBGE). (2017). Futebol é a paixão nacional. Retratos, revista do IBGE. Recuperado de: https://agenciadenoticias.ibge.gov.br/media/c o m $\mathrm{m}$ e $\quad$ d $\quad$ i 99824c28d40d5c38987a16ba9dacc487.pdf

Instituto Nacional de Estudos e Pesquisas Educacionais Anísio Teixeira. (2017). Índice de desenvolvimento de Educação Bá- sica. Recuperado de http://www.qedu.org.br/cidade/264gravatai/ideb/ideb-por-escolas

Magill, R. (1987). Aprendizagem Motora: Conceitos e Aplicações. $2^{\circ}$ ed. São Paulo: Edgard Blucher, p. 136.

Mérida-Serrano. R., Olivares-García M. A., \& González-Alfaya M. E. (2018). Descubrir el mundo con el cuerpo en la infancia. La importancia de los materiales en la psicomotricidad infantil. Retos, (34), 329-336. Recuperado de: https://recyt.fecyt.es/ index.php/retos/article/view/64652

Monsalve A. M. S., \& Sanchéz L. F. M. (2019). Aprendizaje psicomotriz en el área de Educación Física, Recreación y Deportes mediado por el uso de software educativo. Retos, (36), 302-309. Recuperado de https://recyt.fecyt.es/index.php/retos/article/view/67131

Organização Mundial da Saúde (OMS). (2019). Para crecer sanos, los niños tienen que pasar menos tiempo sentados y jugar más. Recuperado de: https://www.who.int/es/newsroom/detail/2404-2019-to-grow-up-healthy-children-need-to-sit-lessandplay-more

Paiva, N., \& Costa, J. S. (2015). A influência da tecnologia na infầncia: desenvolvimento ou ameaça? O portal dos psicólogos, (1646-6977). Recuperado de https://www.psicologia.pt/ artigos/textos/A0839.pdf

Palma L., Guaríglia D. A., \& Marques I. (2016). Análises do desenvolvimento motor de crianças em diferentes clases sociales. Coleção pesquisa em Educação Física, (02), 35-43. Recuperado de: http://www.uel.br/grupopesquisa/gepedam/ prod_cientifica/artigos/art41.pdf

Patraquim, C., Ferreira, S., Martins, Hélder., Mourão, H., Gomes, P., \& Martins, S. (2018). As crianças e a exposição aos media. Nascer e Crescer, v.27, (1), 11-21. Recuperado de http:// www.scielo.mec.pt/scielo.php?script=sci_arttext\&pid= S087207542018000100002\&lng=pt\&nrm=iso

Pazin, J., Frainer, D. E. S., \& Moreira, D. (2006). Crianças obesas têm atraso no desenvolvimento motor. Revista Digital, Ano 11, $\left(N^{\circ} 101\right)$. Buenos Aires.

Programa das Nações Unidas para o Desenvolvimento no Brasil. (2017). Relatório associa esportes e atividades físicas com desenvolvimento humano e alerta sobre a importância do acesso a todos os grupos sociais. O relatório de Desenvolvimento Humano Nacional 2017- Movimento é vida: Atividades Físicas e Esportivas para Todas as Pessoas para o Desenvolvimento no Brasil. Recuperado de http:// www.br.undp.org/content/brazil/pt/home/presscenter/articles/ 2017/09/26/relat-rio-associa-esporte-e-atividades-fisicascomdesenvolvimento-humano-e-alerta-sobre-import-nciadoacesso-atodos-os-grupos-sociais/

Programa das Nações Unidas para o Desenvolvimento no Brasil. Relatório associa esportes e atividades físicas com desenvolvimento humano e alerta sobre a importância do acesso a todos os grupos sociais, (2017). Recuperado de: http:// www.br.undp.org/content/brazil/pt/home/presscenter/articles/ 2017/09/26/relat-rio-associa-esporte-e-atividades-f-sicas-comdesenvolvimento-humano-e-alerta-sobre-import-ncia-doacesso-a-todos-os-grupos-sociais/

Schmidt, R. A., \& Wrisberg, C. A. (2010). Aprendizagem e performance motora. Uma abordagem da aprendizagem baseada na situação. Porto Alegre: $4^{\circ}$ Edição. Editora Artmed. P.416.

Tani G., \& Correa U. C. (2016). Aprendizagem Motora e o ensino do esporte. São Paulo: $1^{\circ}$ Edição Digital. Editora Edgard Blucher Ltda. P.384.

Thomas J. R., Nelson J. K., \& Silverman S. J. (2012). Métodos de pesquisa em atividade física. São Paulo: $6^{\circ}$ Edição. Artmed Editora.

Wagner, A., Tronco, C., Gonçalves, J. S., Demarchi, K. A., \& Levandowski, D. C. (2012). Projetos para os filhos e estratégias de socialização: a perspectiva de pais e mães. Psicologia \& Sociedade, v.24, (1),122-129. Recuperado de http:// www.scielo.br/scielo.php?script $=$ sci_arttext\&pid $=\mathrm{S}$ $010271822012000100014 \& \operatorname{lng}=\mathrm{en} \& \mathrm{nrm}=\mathrm{iso}$ 